UDC 622.69:536

\title{
The use of nanomaterials in pipe insulation
}

\section{Authors:}

Kiyamov Ilgam K., Professor, Doctor of Economics, Kazan (Volga Region) Federal University, Engineering Institute; Kazan, Russia, e-mail: kiyamov.ilgam@mail.ru;

Vachitova Roza II.,

Associate Professor, PhD in Engineering, Almetyevsk State Oil Institute; Almetyevsk, Russia, e-mail: roza-w@mail.ru;

\section{Saracheva Diana A.,}

$\mathrm{PhD}$ in Engineering, Senior Lecturer, Almetyevsk State Oil Institute; Almetyevsk, Russia, e-mail: sarachevadiana85@mail.ru;

\section{Mazankina Daria V.,}

Senior Lecturer, Almetyevsk State Oil Institute; Almetyevsk, Russia, e-mail: daria-mazankina@yandex.ru

\section{Sitdikova Irina P.,}

PhD in Engineering, Associate Professor of Department «Automation and Information Technology», Almetyevsk State Oil Institute, Almetyevsk, Russia

\footnotetext{
Abstract: The nanotechnologies applied in engineering will increase its energy efficiency. The use of nanomaterials will make it possible to reduce costs. Currently, the search for nanomodified materials is relevant for the construction industry. Various carboncontaining structures are used as nanodispersed modifiers. Taunit has been selected as carbon nanomaterial. This nanomaterial is packaged multilayer nanotubes with a conical shape of graphene layers.

To conduct this research samples of foam concrete cements have been studied. To improve the mechanical properties of the cement stone, elongated nanoparticles with high strength were used. They reinforce cement mortar, at the same time being the centers of crystallization and increase the strength of the nanomaterial.

In the course of experiments, carbon nanotubes «Taunit» were added to the foam concrete in the amount of $0.005-0,0005 \%$ by weight of cement. In the manufacture of nanomodified foam concrete it is important to ensure uniform distribution of nanoparticles. The studied cement stone chips were sprayed with Au / Pd alloy in a Quorum 150T ES vacuum unit in a 80/20 ratio. The microstructure of solid samples of cement material was investigated by means of a high-resolution auto-emission electron microscope Merlin of CARL ZEISS.

When multi-layered carbon nanotubes of "Taunit" brand were introduced into the cement mortar, the relief microstructure of the cement was characterized by a heterogeneous and loose structure. In the course of testing the strength of the investigated samples, the following results were obtained: under bending loads applied to cement-sand mortar for 7 days, hardening increased by $35 \%$, and after 28 days - by $30 \%$; under compressive loads, the increase in strength is $42 \%$ and $22 \%$, respectively, relative to the original composition without the addition of nanomodified materials.

The addition of nanodispersed modifiers to the cement stone made it possible to increase the strength of concrete and foam concrete. Based on the obtained nanomodified foam concrete, a device for insulating pipelines has been proposed.
}

Keywords: thermal insulation, pipelines, nanotubes, nanomodified foam concrete, nanomaterials, Taunit, carbon nanotubes.

For citation: Kiyamov I.K., Vachitova R.I., Saracheva D.A., Mazankina D.V., Sitdikova I. P. The use of nanomaterials in pipe insulation. Nanotehnologii v stroitel'stve = Nanotechnologies in Construction. 2019, Vol. 11, no. 2, pp. 194-202. DOI: 10.15828/2075-85452019-11-2-194-202. 
Machine-readable information on CC-licenses (HTML-code) in metadata of the paper

<a rel="license" href="http://creativecommons.org/licenses/by/4.0/"><img alt="Creative Commons License" style="border-width:0" src="https://i.creativecommons. org/l/by/4.0/88x31.png" / ></a $><$ br / ><span xmlns:dct="http://purl.org/dc/terms/" href="http://purl.org/dc/dcmitype/Text" property="dct:title" rel="dct:type" $>$ The use of nanomaterials in pipe insulation. $</$ span $>$ by $<$ a xmlns:cc="http://creativecommons.org/ns\#" href="Nanotehnologii v stroitel'stve $=$ Nanotechnologies in Construction. 2019, Vol. 11, no. 2, pp. 194-202. DOI: 10.15828/2075-8545-2019-11-2-194-202" property="cc:attributionName" rel="cc:attributionURL">Kiyamov I.K., Vachitova R.I., Saracheva D.A., Mazankina D.V., Sitdikova I.P. $</$ a $>$ is licensed under a $<$ a rel="license" href="http://creativecommons.org/licenses/by/4.0/" $>$ Creative Commons Attribution 4.0 International License</a $>$.<br/>Based on a work at $<$ a xmlns:dct="http://purl.org/dc/terms/" href="http://nanobuild.ru/en_EN/nanobuild-2-2019/" rel="dct:source" $>$ http://nanobuild.ru/en_EN/nanobuild-2-2019/</a $>.<\mathrm{br} />$ Permissions beyond the scope of this license may be available at $<$ a xmlns:cc="http://creativecommons.org/ns\#" href="sarachevadiana85@mail.ru" rel="cc:morePermissions" $>$ sarachevadiana85@mail.ru</a $>$.

The paper has been received by editors: 30.12 .2018 .

\section{Применение наноматериалов в теплоизоляции трубопроводов}

\section{Авторы:}

Киямов Ильгам Киямович,

доктор экономических наук, профессор, Казанский (Приволжский) федеральный университет, Инженерный институт; Казань, Россия, e-mail: kiyamov.ilgam@mail.ru;

\section{Вахитова Роза Ильгизовна,}

доцент, кандидат технических наук, Альметьевский государственный нефтяной институт; Альметьевск, Россия, e-mail: roza-w@mail.ru;

\section{Сарачева Диана Азатовна,}

кандидат технических наук, старший преподаватель, Альметьевский государственный нефтяной институт;

Альметьевск, Россия, е-mail: sarachevadiana85@mail.ru;

\section{Мазанкина Дарья Владимировна,}

старший преподаватель, Альметьевский государственный нефтяной институт; Альметьевск, Россия, e-mail: daria-mazankina@yandex.ru

\section{Ситдикова Ирина Петровна,}

кандидат технических наук, доцент кафедры «Автоматизация и информационные технологии», Альметьевский государственный нефтяной институт; Альметьевск, Россия

Резюме: Применение нанотехнологий в строительстве позволит повысить его энергетическую эффективность. Использование наноматериалов даст возможность уменьшить затраты. В настоящий момент для строительной отрасли актуален поиск наномодифицированных материалов. В качестве нанодисперсных модификаторов применяют различные углеродосодержащие структуры. Выбрали разновидность углеродного наноматериала, как «Таунит». Этот наноматериал представляет собой пакетированные многослойные нанотрубки с конической формой графеновых слоев.

Для выполнения исследований рассмотрены образцы цементов пенобетона. Для улучшения физико-механических свойств цементного образца применили наночастицы вытянутой формы, которые обладают достаточно высокой прочностью. Эти частицы армируют раствор цемента, одновременно являются центрами кристаллизации и увеличивают прочность наноматериала.

В процессе проведения экспериментов в пенобетон добавили углеродные нанотрубки «Таунит» в объеме 0,005-0,0005\% от массы цемента. При изготовлении наномодифицированного пенобетона важно обеспечить равномерное распределение наночастиц. Исследуемые сколы цементного камня напыляли сплавом Au/Pd в вакуумной установке Quorum 150T ES в соотношении 80/20. Микроструктуры твердотельных образцов цементного материала исследовали с применением высокоразрешающего автоэмиссионного электронного микроскопа Merlin компании CARL ZEISS. 
STUDY OF PROPERTIES OF NANOMATERIALS • ИССЛЕДОВАНИЕ СВОЙСТВ НАНОМАТЕРИАЛОВ

При введении многослойных углеродных нанотрубок марки «Таунит» в цементный раствор рельефная микроструктура цемента отличалась неоднородной и рыхлой структурой. В процессе испытания на прочность исследуемых образцов были получены следующие результаты: при изгибающих нагрузках цементного раствора после 7 суток процесс затвердевания повысился на 35\%, а после 28 суток - на 30\%; при сжимающих нагрузках процесс увеличения прочности составил $42 \%$ и $22 \%$ соответственно, по отношению к первоначальному составу цементно-песчаного раствора без добавления наномодифицированных частиц.

Добавление в цементный камень нанодисперсных модификаторов позволило увеличить прочность бетонов и пенобетонов. На основе полученного наномодифицированного пенобетона предлагается устройство теплоизоляции трубопроводов.

Ключевые слова: теплоизоляция, трубопровод, нанотрубка, наномодифицированный пенобетон, наноматериалы, Таунит, углеродные нанотрубки.

Для цитирования: Киямов И.К., Вахитова Р.И., Сарачева Д.А., Мазанкина Д.В., Ситдикова И.П. Применение наноматериалов в теплоизоляции трубопроводов // Нанотехнологии в строительстве. - 2019. - Том 11, № 2. - 194-202 c. - DOI: 10.15828/20758545-2019-11-2-194-202.

Machine-readable information on CC-licenses (HTML-code) in metadata of the paper

$<$ a rel="license" href="http://creativecommons.org/licenses/by/4.0/"><img alt="Creative Commons License" style="border-width:0" src="https://i.creativecommons. org///by/4.0/88x31.png"/></a $><$ br / ><span xmlns:dct="http://purl.org/dc/terms/" href="http://purl.org/dc/dcmitype/Text" property="dct:title" rel="dct:type" $>$ The use of nanomaterials in pipe insulation. $</$ span $>$ by $<$ a xmlns:cc="http://creativecommons.org/ns\#" href="Nanotehnologii v stroitel'stve $=$ Nanotechnologies in Construction. 2019, Vol. 11, no. 2, pp. 194-202. DOI: 10.15828/2075-8545-2019-11-2-194-202" property="cc:attributionName" rel="cc:attributionURL">Kiyamov I.K., Vachitova R.I., Saracheva D.A., Mazankina D.V., Sitdikova I.P. $</$ a $>$ is licensed under a $<$ a rel="license" href="http://creativecommons.org/licenses/by/4.0/" $>$ Creative Commons Attribution 4.0 International License</a $>$. $<$ br />Based on a work at $<$ a xmlns:dct="http://purl.org/dc/terms/" href="http://nanobuild.ru/en_EN/nanobuild-2-2019/" rel="dct:source" $>$ http://nanobuild.ru/en_EN/nanobuild-2-2019/ $</ a>.<b r />$ Permissions beyond the scope of this license may be available at $<$ a $x m l n s: c c="$ http://creativecommons.org/ns\#" href="sarachevadiana85@mail.ru" rel="cc:morePermissions" $>$ sarachevadiana85@mail.ru</a $>$.

Статья поступила в редакцию: 30.12 .2018$.

Статья поступила в редакцию после рецензирования: 15.02.2019.

Статья принята к публикации: 01.03.2019.

\section{ВВЕДЕНИЕ}

В строительстве нанотехнологии - это технологические решения, позволяющие увеличить энергетическую эффективность комплекса и уменьшить затраты за счет применения наноматериалов. Использование традиционных технологий за последние десятилетия в строительной отрасли уже исчерпало свои возможности, поэтому востребованы новые инновационные решения. Внедрение современных нанотехнологий позволит повысить эффективность строительства [1..4].

Нанотехнология - это создание и использование материалов, систем и устройств, в которых структура регулируется в нанометровом интервале, т.е. в размере атомов, молекул и надмолекулярных образований $[5,6]$.

\section{1. Выбор наномодифицированной добавки}

Для строительной отрасли в настоящий момент идет активный поиск наномодифицированных ма- териалов, представляющих собой традиционные материалы с добавлением малых частиц размером порядка нескольких микро- и нанометров для улучшения свойств и характеристик материалов $[7,8]$. Существует несколько видов нанодобавок. В качестве примера нанодобавки можно рассмотреть углеродные нанотрубки (УНТ) [9].

УНТ представляют собой цилиндрические протяжённые структуры, которые имеют длину до нескольких сантиметров и диаметр также в диапазоне до нескольких десятков нанометров (имеются технологии, которые позволяют сплетать их в нити различной длины) [10]. Эти структуры состоят из одной или нескольких свёрнутых в трубку графеновых плоскостей, они обычно заканчиваются головкой полусферической формы, которая может рассматриваться как часть молекулы фуллерена. Механизм образования фуллеренов в настоящее время точно не установлен, поэтому имеется предположение, что они образуются из атомов углерода, соединяющихся в слой сочлененных шестичленных бензольных колец, а затем в какой-то момент свора- 
чивающих этот слой в тот или иной многогранник [11...17].

Для проведения исследований рассмотрены образцы цементов пенобетона. С целью улучшения механических свойств цементных камней более рациональным является использование вытянутых наночастиц, которые характеризуются высокой прочностью, инертными свойствами к щелочам и кислотам. Данные наночастицы армируют цементно-песчаный раствор и становятся кристаллизационными центрами, в итоге материал увеличивает прочность.

Наноматериалы и наночастицы имеют комплекс физических, химических свойств и биологическое действие, которые чаще всего радикально отличаются от свойств и действия этого вещества в виде макроскопических дисперсий или сплошных фаз. Наноматериалы обладают очень высокой удельной поверхностью (при расчете на единицу массы), то есть обладают свойствами высокоэффективных адсорбентов из-за их высокой адсорбционной емкости, химической реакционной способности и каталитических свойств.

Наночастицы имеют возможность формировать различные структурные системы (элементы), могут быть одномерными, двумерными, трехмерными, фрактальными и образовывать их комбинации. Нанотехнологическое пространство обладает размерами, в которых происходят такие явления как: самоорганизация, синергетическое взаимодействие изменяющихся элементов. Метрический диапазон нанопространства находится в пределах 0,5-100 нм [18].

2. Модификация цементного камня углеродными нанодобавками

Для модифицирования структуры цементных камней наноразмерными частицами применяются два направления:
- целенаправленный процесс выращивания в твердеюще-вяжущей среде микрочастиц, которые необходимы для модифицирования структуры до наноразмеров;

- предварительный процесс синтеза микроскопических частиц и дальнейшее введение их в бетонный раствор.

Чаще всего встречается на практике второй метод, однако из-за высокой поверхностной активности углеродных нанотрубок при синтезе они приобретают форму конгломератов из порошковых гранул, что ведет к затруднению их равномерного распределения по всему объему композиционного материала. В результате данный процесс приводит к образованию материала с высокой неоднородностью по плотности, прочности и другим свойствам.

В качестве нанодисперсных модификаторов используют различные углеродосодержащие структуры наноматериалов (УНМ). Выбрали такую разновидность УНМ как «Таунит», представляющую собой пакетированные многослойные нанотрубки, имеющие преимущественно коническую форму графеновых слоев. Основные параметры УНМ разновидности «Таунит» представлены в табл. [19...21].

Гранулы УНМ имеют микрометрические размеры и структуру в виде спутанных пучков углеродных многостенных нанотрубок.

В процессе проведения экспериментов пенобетон содержал в своем составе углеродные нанотрубки марки «Таунит» в количестве $0,005-0,0005 \%$ от общей массы цемента.

В процессе изготовления наномодифицированного пенобетона важным является обеспечение равномерного распределения наночастиц, являющихся инициаторами схватывания цемента, в объеме бетона [22].

Микроструктуры образцов цемента исследовались с применением высокоразрешающего электронного микроскопа Merlin компании CARL ZEISS,

\section{Таблица}

Параметры углеродного наноматериала «Таунит»

\begin{tabular}{|c|c|c|c|c|c|c|c|}
\hline \multirow[b]{2}{*}{$\begin{array}{c}\text { Вид угле- } \\
\text { родсодер- } \\
\text { жащего } \\
\text { материала }\end{array}$} & \multicolumn{7}{|c|}{ Параметры УНМ } \\
\hline & $\begin{array}{c}\text { Диаметр } \\
\text { внешний, нм }\end{array}$ & $\begin{array}{c}\text { Диаметр } \\
\text { внутренний, } \\
\text { нм }\end{array}$ & $\begin{array}{c}\text { Объем } \\
\text { примесей } \\
\text { общий, \% }\end{array}$ & Длина, мкм & $\begin{array}{c}\text { Термоста- } \\
\text { бильность, } \\
{ }^{\circ} \mathrm{C}\end{array}$ & \begin{tabular}{|c|} 
Поверх- \\
ность удель- \\
ная геоме- \\
трическая, \\
м²/г \\
\end{tabular} & 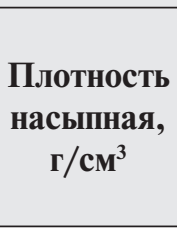 \\
\hline Таунит & $20-70$ & $5-10$ & до 1 & 2 и более & до 600 & 120 и более & $0,4-0,6$ \\
\hline Таунит-М & $30-80$ & $10-20$ & до 1 & 20 и более & до 600 & $180-200$ & $0,03-0,05$ \\
\hline Таунит-МД & $8-15$ & $4-8$ & до 1 & 2 и более & до 600 & 300 и более & $0,03-0,05$ \\
\hline
\end{tabular}


предназначенного для измерений линейных размеров микрорельефа твердотельных структур.

Сколы исследуемых образцов цементного материала в соотношении 80/20 напыляли сплавом Au/ Pd в вакуумной установке Quorum 150T ES. Универсальная система Q150T ES позволяет работать в режиме напыления металлами и углеродом, с автоматической системой контроля вакуума и с возможностью программирования для напыления различных материалов.

Выявлено, что введение однослойных УНТ марки «Таунит» характеризуется процессом образования плотной однородной и более мелкой кристаллической структуры в сравнении с контрольным образцом цементно-песчаного материала. При введении многослойных УНТ марки «Таунит» в цементный раствор микроскопическая структура цементного образца характеризуется рыхлой и неоднородной структурой [2].

Добавление в цементный раствор нанодисперсных модификаторов позволяет повысить прочность бетонных и пенобетонных материалов.

При добавлении в раствор цемента частиц «Таунит» прочностные характеристики при изгибающих нагрузках цементно-песчаной композиции по истечению 7 суток при нормальном затвердевании увеличиваются на $35 \%$, по истечению 28 суток - на 30\%, при сжимающих нагрузках повышение ее прочностных характеристик стало равным $42 \%$ и $22 \%$, соответственно, по отношению к первоначальному составу без добавления наномодифицированных частиц.
В процессе модификации цементного раствора УНТ наблюдается более мелкая кристаллическая структура, это объясняет процесс повышения прочностных характеристик при испытаниях на сжатие и изгиб модифицированного цементно-песчаного раствора.

Для выполнения экспериментов использовалось аналитическое оборудование для фундаментальных исследований свойств наноструктур и наноматериалов Центра нанотехнологий Республики Татарстан, Междисциплинарного центра «Аналитическая микроскопия» Казанского федерального университета, научной лаборатории «Нанотехнологии в строительстве» Казанского государственного архитектурностроительного университета.

3. Теплоизоляционный материал с применением наномодифицированного пенобетона

Для снижения потерь тепловой энергии при транспортировке теплоносителей рекомендуется применение теплоизоляции трубопроводов с добавлением различных композиционных материалов. Авторы предлагают использовать в качестве теплоизоляционного материала наномодифицированный монолитный пенобетон. В качестве компонента изоляционного материала использованы углеродосодержащие наноструктуры [23, 24].

На основе полученного наномодифицированного пенобетона предлагается устройство теплоизоляции трубопроводов, которое представлено на рис.

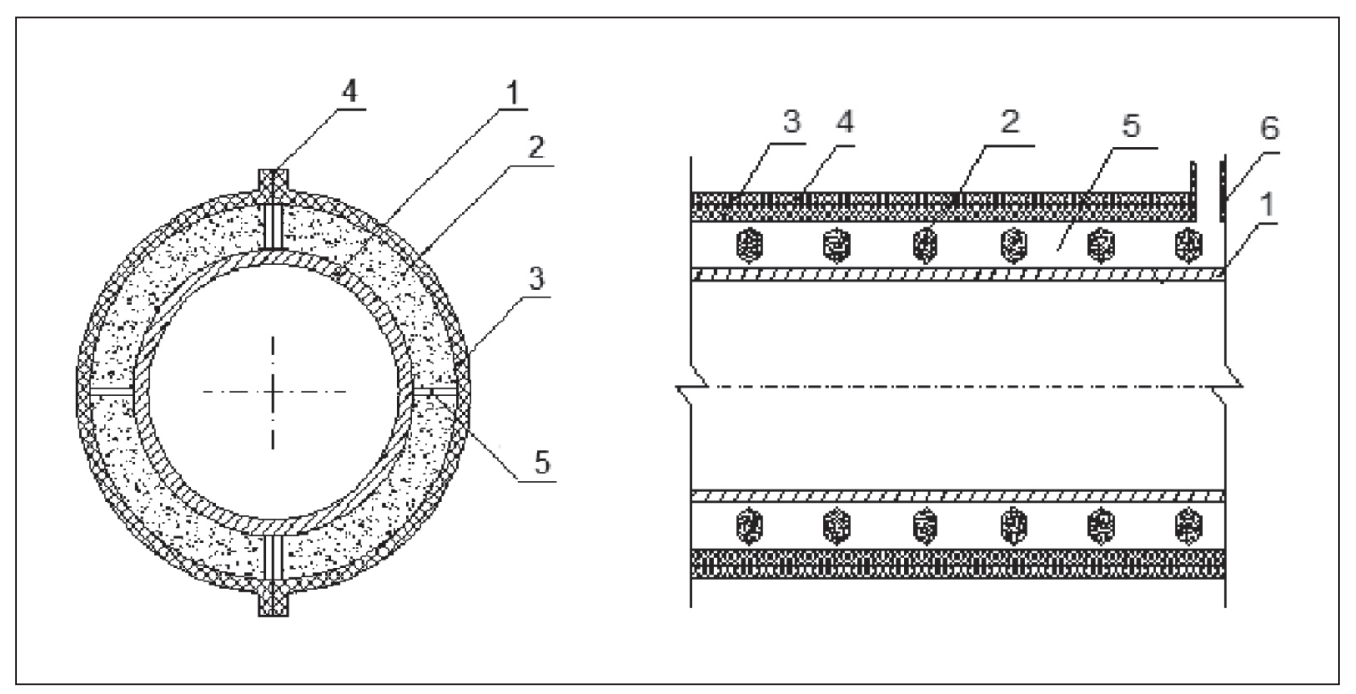

Рис. Конструкция нанотеплоизоляции тепло- и нефтетрубопровода: 1 - трубопровод, 2 - наномодифицированный монолитный пенобетон, 3 - оболочка, 4 - крепление, 5 -диафрагма, 6 - воронка для подачи наномодифицированного монолитного пенобетона;

а) поперечное сечение; б) продольное сечение 
Теплоизоляция трубопроводов наносится на трубопровод 1 и состоит из монолитного наномодифицированного пенобетона 2, пластиковой оболочки 3 , крепления опалубки между собою 4 , специальных диафрагм жесткости 5, воронки для подачи наномодифицированного пенобетона 6.

Процесс нанесения теплоизоляции заключается в проведении следующих технологических операций: устанавливается опалубка из пластиковой оболочки, приготавливается пенобетон с использованием углеродных нанотрубок марки «Таунит». Затем приготовленный наномодифицированный пенобетон подается в установленную опалубку.

Геометрические размеры опалубки зависят от диаметра трубопровода. Специальная пластиковая опалубка в зависимости от требований, предъявляемых к нему, может изготавливаться любой конфигурации.

Предлагаемый способ теплоизоляции трубопроводов с использованием УНТ в составе монолитного пенобетона может использоваться как при новом строительстве, так и при реконструкции существующих трубопроводов.

Монолитный наномодифицированный пенобетон изготавливается на специализирующемся заводе и доставляется к месту строительства автомобильным транспортом [25].

Разработка наномодифицированного монолитного пенобетона направлена на повышение долговечности и эксплуатационной надежности теплотрубопроводов, малую трудоемкость изготовления теплоизоляции, снижение потерь тепловой энергии при транспортировке теплоносителя при одновременном сокращении сроков изготовления теплоизоляции.

Трубопроводы с теплоизоляцией из наномодифицированного пенобетона имеют высокий срок службы и низкую теплопроводность, отличаются простотой выполнения монтажных работ.

На основе выполнения экспериментов по созданию наномодифицированного пенобетона получены патент РФ на полезную модель № 154256 [26] и свидетельство о государственной регистрации программы для ЭВМ № 2014663065 [27].

Технология изготовления наномодифицированных пенобетонов не требует нового технологического оборудования, а их стоимость увеличивается не более чем на 10-20\%. Преимущества нанобетонов определяются особой микроструктурой, формируемой вследствие самоорганизации цементного раствора на наноуровне.

Применение наномодифицированных бетонов в строительной отрасли ТЭК может дать большой экономический и экологический эффект [7].

\section{ЗАКЛЮЧЕНИЕ}

Разработана разновидность теплоизоляции из наномодифицированного пенобетона, имеющего в составе углеродные нанотрубки марки «Таунит». Применение наномодифицированных добавок в составе пенобетона позволило увеличить прочность цементного камня на $20 \%$.

\section{REFERENCES}

1. Foster L.E. Nanotekhnologii. Nauka, innovatsii i vozmozhnosti [Nanotechnology. Science, Innovation and Opportunity]. Moscow, Technosphere, 2008. 352 p. (in Russian)

2. Dixon J.B. Diversity of natural nanoparticles in soils and causative factors implied. Mineralogia - Special Papers: $4^{\text {th }}$ MidEuropean Clay Conference MECC, Zakopane, Poland, 2008. p. 54.

3. Patrikeev L.N. Nanotekhnologii v energetike [Nanotechnologies in power engineering]. Nanoindustry. 2008. № 2. p. 14-15. (in Russian).

4. Mccarty D.K. Mineral analysis and energy industry applications. Mineralogia - Special Papers: $4^{\text {th }}$ Mid-European Clay Conference MECC, Zakopane, Poland, 2008. p. 112.

5. Roko M.K., Williams R.S., Alivatos P. Nanotekhnologii v blizhaysheye desyatiletiye. Prognoznyye napravleniya issledovaniy [Nanotechnology in the coming decade. Forecast areas of research]. Moscow, World, 2002. p. 292.

6. Brat S., Singh P. Use of Nanorobots in Oil Industry. Maharashtra Institute of Technology, 2006. SPE Mumbai Section.

7. Khavkin A.Ya. Nanoyavleniya i nanotekhnologii v dobyche nefti i gaza [Nanotechnologies and nanotechnologies in oil and gas production]. Moscow. Izhevsk, SIC «Regular and chaotic dynamics», Institute for Computer Studies, 2010. p. 692. (in Russian).

8. Detlef B., Klaus S. Chemomechanical processing - the innovative way of integrating nanoparticles into industrial products. PETROTECH, New Delhi, India. 2009. p. 286.

9. Mazurenko V.V., Rudenko A.N., Mazurenko V.G. Nanochastitsy, nanomaterialy, nanotekhnologii. Uchebnoye posobiye [Nanoparticles, nanomaterials, nanotechnologies]. Tutorial. Yekaterinburg: Federal Agency for Education, Ural State Technical University - UPI them. first President of Russia B.N. Yeltsin. 2009. p. 83. (in Russian). 
STUDY OF PROPERTIES OF NANOMATERIALS • ИССЛЕДОВАНИЕ СВОЙСТВ НАНОМАTEРИАЛОВ

10. Mishchenko S.V., Tkachev A.G. Uglerodnyye nanomaterialy. Proizvodstvo, svoystva, primeneniye [Carbon nanomaterials. Production, properties, application]. Moscow. Mechanical Engineering, 2008. (in Russian).

11. Kehl A.V. Fullereny i uglerodnyye nanotrubki [Fullerenes and carbon nanotubes]. Innovation science. 2016. № 11-3. p. 23-25. (in Russian).

12. Zakirnichnaya M.M. Obrazovaniye fullerenov v uglerodistykh stalyakh i chugunakh pri kristallizatsii i termicheskikh vozdeystviyakh [The formation of fullerenes in carbon steels and cast irons during crystallization and thermal effects]. Ufa. Gilem. 2002. p. 180. (in Russian).

13. Zaporotskova I.V. Uglerodnyye i neuglerodnyye nanomaterialy i kompozitnyye struktury na ikh osnove: stroyeniye i elektronnyye svoystva [Carbon and non-carbon nanomaterials and composite structures based on them: structure and electronic properties]. Volgograd. Publishing house of the Volgograd State the university. 2009. p. 488. (in Russian).

14. Rayfti, S., Chegini, E. K. Highly selective and green oxidation of sulfides with urea hydrogen peroxide in the presence of MN (III) porphyrin supported onto carbon nanotubes. Makrogeterotsikly. 2016. Vol. 9, No 2. P. 151-155. DOI: 10.6060/mhc151101r.

15. Khussein S.M.R.H., Hanfar A. Uglerodnyye nanotrubki: problemy i perspektivy ikh ispolzovaniya [Carbon nanotubes: problems and prospects for their use]. Advances in modern science. 2017. Vol. 4, No 4. pp. 166-169. (in Russian).

16. Salamatov V.I., Vasilyeva K.S. Uglerodnyye nanotrubki - osnova perspektivnykh nanomaterialov [Carbon nanotubes - the basis of promising nanomaterials]. Life cycle of structural materials (from receipt to disposal): materials of reports of the Vth AllRussian Scientific and Technical Conference with international participation. Irkutsk. 2015. pp. 247-254. (in Russian).

17. Lebeda Yu.V. Uglerodnyye nanotrubki: ikh svoystva i metody modifikatsii [Carbon nanotubes: their properties and methods of modification]. Nedelya nauki SPbGPU: materialy XLII nauchno-prakticheskoy konferentsii c mezhdunarodnym uchastiyem (SPbGPU Science Week: Proceedings of the XLII Scientific Practical Conference with international participation). St. Petersburg. 2014. p. 30-32. (in Russian).

18. Shevchenko V.Ya. Institut khimii silikatov RAN. Issledovaniya v oblasti nanomira i nanotekhnologiy [Institute of Silicate Chemistry RAS. Research in the field of nanoworld and nanotechnology]. Russian nanotechnology. 2008. Vol. 3, No 11-12. pp. 36-45. (in Russian).

19. Kiyamov I.K., Mingazov R.Kh., Vakhitova R.I., Muzafarov A.F., Kiyamova L.I., Sibgatullin A.A., Saracheva D.A., Mazankina D.V., Abramova El.V. Vliyaniye UNT «Taunit» na teplotekhnicheskiye i fiziko-mekhanicheskiye svoystva bitumov [The effect of CNT «Taunit» on the thermal and physico-mechanical properties of bitumen]. Proceedings of the scientific session of the scientists of the Almetyevsk State Oil Institute. Almetyevsk. 2015. Vol. 1, No 1. pp. 3-8. (in Russian).

20. Tkachev AG, Melezhik AV, Dyachkova TP, Blokhin AN, Burakova EA, Pasko T.V. Uglerodnyye nanomaterialy serii «Taunit»: proizvodstvo i primeneniye [Carbon nanomaterials of the «Taunit» series: production and use]. Proceedings of higher educational institutions. Series: Chemistry and Chemical Technology. 2013. Vol. 56, No 4. pp. 55-59. (in Russian).

21. Falikman V.R. Nanomaterials and nanotechnologies in modern concretes. Industrial and civil engineering. 2013. No 1. pp. 31-34. (in Russian).

22. Ponomarev A.N. Nanobeton - ponyatiye i problemy. Sinergizm nanostrukturirovannykh tsementnykh vyazhushchikh i anizotropnykh dobavok [Nanobeton - the concept and problems. Synergism of nanostructuring cement binders and anisotropic additives]. Construction materials. 2007. No 6. (in Russian).

23. Voytovich V.A., Khryapchenkova I.N. Nanobeton v stroitelstve [Nanobeton in construction]. Construction materials. 2016. № 9. pp. 73-75. (in Russian).

24. Kudyakov A.I., Steshenko A.B. Penobeton dispersno-armirovannyy teploizolyatsionnyy yestestvennogo tverdeniya [Foam concrete disperse-reinforced heat-insulating natural hardening]. Bulletin of Tomsk State University of Architecture and Civil Engineering. 2014. - No 2 (43). pp. 127-133. (in Russian).

25. Kiyamov I.K., Mingazov R.Kh., Vakhitova R.I., Kiyamova L.I., Sibgatullin A.A., Saracheva D.A., Mazankina D.V. Vozmozhnosti primeneniya nanoteploizolyatsii truboprovodov na obyektakh po dobyche vysokovyazkikh neftey [Possibilities of application of nanoheat insulation of pipelines at facilities for the extraction of highly viscous oils]. Proceedings of the scientific session of the scientists of the Almetyevsk State Oil Institute. Almetyevsk. 2016. Vol. 2. pp. 51-53. (in Russian).

26. Kiyamov I.K., Mingazov R.Kh., Muzafarov A.F., Ibragimov R.A., Kiyamova L.I. Ustroystvo nanoteploizolyatsii teplo i neftetruboprovodov [The device nanoteploizolyatsii heat - and oil pipelines]. Patent RF № 154256. 2015. (in Russian).

27. Kiyamov I.K., Mingazov R.Kh., Muzafarov A.F., Zagretdinov A.R., Ibragimov R.A., Kiyamova L.I. Programma dlya rascheta teploizolyatsii iz nanomodifitsirovannogo betona nefteprovodov [Program for calculating the insulation of nanomodified concrete pipelines]. Certificate of state registration of computer programs № 2014663065. 2014. (in Russian).

\section{СПИСОК ЛИТЕРАТУРЫ}

1. Фостер Л.Э. Нанотехнологии. Наука, инновации и возможности. - М.: Техносфера, 2008. - 352c.

2. Dixon J.B. Diversity of natural nanoparticles in soils and causative factors implied // Mineralogia - Special Papers: $4^{\text {th }}$ MidEuropean Clay Conference MECC, Zakopane, Poland, 2008. P. 54.

3. Патрикеев Л.Н. Нанотехнологии в энергетике // Наноиндустрия. - 2008. - № 2. - С. 14-15.

4. Mccarty D.K. Mineral analysis and energy industry applications. Mineralogia - Special Papers: $4^{\text {th }}$ Mid-European Clay Conference MECC, Zakopane, Poland, 2008. P. 112. 
STUDY OF PROPERTIES OF NANOMATERIALS • ИССЛЕДОВАНИЕ СВОЙСТВ НАНОМАTЕРИАЛОВ

5. Роко М.К., Уильямс Р.С., Аливатос П. Нанотехнология в ближайшем десятилетии. Прогноз направления исследований. - М.: Мир, 2002. - 292с.

6. Brat S., Singh P. Use of Nanorobots in Oil Industry. Maharashtra Institute of Technology, 2006. SPE Mumbai Section

7. Хавкин А.Я. Наноявления и нанотехнологии в добыче нефти и газа. - Москва - Ижевск: НИЦ «Регулярная и хаотическая динамика», Институт компьютерных исследований, 2010. - 692 с.

8. Detlef B., Klaus S. Chemomechanical processing - the innovative way of integrating nanoparticles into industrial products // PETROTECH, New Delhi, India. 2009. P. 286.

9. Мазуренко В.В., Руденко А.Н., Мазуренко В.Г. Наночастицы, наноматериалы, нанотехнологии. Учебное пособие. - Екатеринбург: Федеральное агентство по образованию, Уральский гос. технический ун-т - УПИ им. первого Президента России Б.Н. Ельцина, 2009. - 83 с.

10. Мищенко С.В., Ткачев А.Г. Углеродные наноматериалы. Производство, свойства, применение. - М.: Машиностроение, 2008.

11. Кель А.В. Фуллерены и углеродные нанотрубки // Инновационная наука. - 2016. - № 11-3. - С. $23-25$.

12. Закирничная М.М. Образование фуллеренов в углеродистых сталях и чугунах при кристаллизации и термических воздействиях. - Уфа: Гилем, 2002. - 180 с.

13. Запороцкова И.В. Углеродные и неуглеродные наноматериалы и композитные структуры на их основе: строение и электронные свойства. - Волгоград: Изд-во Волгоградского гос. ун-та. $-2009 .-488$ с.

14. Rayfti, S., Chegini, E. K. Highly selective and green oxidation of sulfides with urea hydrogen peroxide in the presence of MN (III) porphyrin supported onto carbon nanotubes // Макрогетероциклы. - 2016. - Т. 9, № 2. - C. 151-155. DOI: 10.6060/ mhc151101r.

15. Хуссейн С.М.Р.Х., Ханфар А. Углеродные нанотрубки: проблемы и перспективы их использования // Успехи современной науки. - 2017. - Т. 4, № 4. - С. 166-169.

16. Саламатов В.И., Васильева К.С. Углеродные нанотрубки - основа перспективного наноматериала // Жизненный цикл конструкционных материалов (от получения до утилизации): материалы докладов V Всероссийской научно-технической конференции с международным участием. - Иркутск, 2015. - С. 247-254.

17. Лебеда Ю.В. Углеродные нанотрубки: их свойства и методы модификации // Неделя науки СПбГПУ: материалы XLII научно-практической конференции с международным участием. - Санкт-Петербург, 2014. - C. 30-32.

18. Шевченко В.Я. Институт химии силикатов РАН. Исследования в области наномира и нанотехнологий // Российские нанотехнологии. - 2008. - Т. 3, № 11-12. - С. 36-45.

19. Киямов И.К., Сибгатуллин А.А., Мингазов Р.Х., Музафаров А.Ф., Киямова Л.И., Almaz А.S., Вахитова Р.И., Сарачева Д.А., Абрамова Э.В., Мазанкина Д.В. Влияние УНТ «Таунит» на теплотехнические и физико-механические свойства битумов // Материалы научной сессии ученых Альметьевского государственного нефтяного института. - Альметьевск, 2015. - Т. 1, № 1. - С. 3-8.

20. Ткачев А.Г., Мележик А.В., Дьячкова Т.П., Блохин А.Н., Буракова Е.А., Пасько Т.В. Углеродные наноматериалы серии «Таунит»: производство и применение // Известия высших учебных заведений. Серия: Химия и химическая технология. - 2013. - Том 56, № 4. - С. 55-59.

21. Фаликман В.Р. Наноматериалы и нанотехнологии в современных бетонах // Промышленное и гражданское строительство. - 2013. - № 1. - С. 31-34.

22. Пономарев А.Н. Нанобетон - концепция и проблемы. Синергизм наноструктурирования цементных вяжущих и анизотропных добавок // Строительные материалы. - 2007. - № 6.

23. Войтович В.А., Хряпченкова И.Н. Нанобетон в строительстве // Строительные материалы. - 2016. - № 9. С. $73-75$.

24. Кудяков А.И., Стешенко А.Б. Пенобетон дисперсно-армированный теплоизоляционный естественного твердения // Вестник Томского государственного архитектурно-строительного университета. - 2014. - № 2 (43). - С. 127 -133.

25. Киямов И.К., Вахитова Р.И., Мингазов Р.Х., Киямова Л.И., Сибгатуллин А.А., Сарачева Д.А., Мазанкина Д.В. Возможности применения нанотеплоизоляции трубопроводов на объектах по добыче высоковязких нефтей // Материалы научной сессии ученых Альметьевского государственного нефтяного института. - Альметьевск, 2016. - Т. 2. - С. $51-53$.

26. Киямов И.К., Мингазов Р.Х., Музафаров А.Ф., Ибрагимов Р.А., Киямова Л.И. Устройство нанотеплоизоляции тепло- и нефтетрубопроводов // Патент РФ № 154256. 2015.

27. Киямов И.К., Мингазов Р.Х., Музафаров А.Ф., Загретдинов А.Р., Ибрагимов Р.А., Киямова Л.И. Программа для расчета теплоизоляции из наномодифицированного бетона нефтепроводов. Свидетельство о государственной регистрации программы для ЭВМ № 2014663065. - 2014 г. 


\section{INFORMATION ABOUT THE AUTHORS}

Kiyamov Ilgam K., Engineering Institute, Doctor of Economics, Professor, Department of Biomedical Engineering and Innovation Management, Kazan (Volga Region) Federal University; Kremlin st., 18, Kazan, Republic of Tatarstan, the Russian Federation, 420008, kiyamov.ilgam@mail.ru;

Vachitova Roza II., PhD in Engineering, Associate Professor, Department «Electrical and Thermal Power Engineering, Almetyevsk State Oil Institute»; Lenina st., 2a, Almetyevsk, Republic of Tatarstan, the Russian Federation, 423450, roza-w@mail.ru;

Saracheva Diana A., PhD in Engineering, Senior Lecturer, Department «Electrical and Thermal Power Engineering», Almetyevsk State Oil Institute; Lenina st., 2a, Almetyevsk, Republic of Tatarstan, the Russian Federation, 423450, sarachevadiana85@mail.ru;

Mazankina Daria V., Senior Lecturer, Department «Electrical and Heat Power Engineering», Almetyevsk State Oil Institute; Lenina st., 2a, Almetyevsk, Republic of Tatarstan, the Russian Federation, 423450, daria-mazankina@yandex.ru

Sitdikova Irina P., Candidate of Technical Sciences, Associate Professor, Department «Automation and information technology «, Almetyevsk State Oil Institute; Lenina st., 2a, Almetyevsk, Republic of Tatarstan, the Russian Federation, 423450, sitdikova_ip@mail.ru

\section{ИНФОРМАЦИЯ ОБ АВТОРАХ}

Киямов Ильгам Киямович, доктор экономических наук, профессор кафедры «Биомедицинская инженерия и управление инновациями», Инженерный институт, Казанский (Приволжский) федеральный университет; ул. Кремлевская, д. 18, г. Казань, Республика Татарстан, Россия, 420008, kiyamov.ilgam@mail.ru;

Вахитова Роза Ильгизовна, кандидат технических наук, доцент кафедры «Электро- и теплоэнергетика», Альметьевский государственный нефтяной институт; ул. Ленина, 2а, г. Альметьевск, Республика Татарстан, Россия, 423450, roza-w@mail.ru

Сарачева Диана Азатовна, кандидат технических наук, старший преподаватель кафедры «Электрои теплоэнергетика», Альметьевский государственный нефтяной институт; ул. Ленина, 2а, г. Альметьевск, Республика Татарстан, Россия, 423450, e-mail: sarachevadiana85@mail.ru;

Мазанкина Дарья Владимировна, старший преподаватель кафедры «Электро- и теплоэнергетика», Альметьевский государственный нефтяной институт; ул. Ленина, 2а, г. Альметьевск, Республика Татарстан, Россия, 423450, daria-mazankina@yandex.ru

Ситдикова Ирина Петровна, кандидат технических наук, доцент кафедры «Автоматизация и информационные технологии», Альметьевский государственный нефтяной институт; ул. Ленина, 2а, г. Альметьевск, Республика Татарстан, Россия, 423450, sitdikova_ip@mail.ru 